\title{
Atividade Alelopática de Substâncias Químicas Isoladas do Capim-MaRandu E SUAS VARIAÇões EM FUNÇÃo DO PH ${ }^{1}$
}

\author{
Allelopathic Activity of Chemical Substances Isolated from Brachiaria brizantha cv. Marandu \\ and their Variations in Function of $p H$
}
SANTOS, L.S. ${ }^{2}$, SANTOS, J.C.L. ${ }^{2}$, SOUZA FILHO, A.P.S. ${ }^{3}$, CORREA, M.J.C. ${ }^{2}$, VEIGA, T.A.M. ${ }^{2}$, FREITAS, V.C.M. ${ }^{2}$, FERREIRA, I.C.S. ${ }^{2}$, GONÇALVES, N.S. ${ }^{2}$, SILVA, C.E. ${ }^{2}$ e GUILHON, G.M.S.P. ${ }^{2}$

\begin{abstract}
RESUMO - Este trabalho teve por objetivos isolar, identificar e caracterizar a atividade alelopática de substâncias químicas produzidas pela Brachiaria brizantha cv. Marandu e determinar as variações na atividade dessas substâncias em função da variação do $\mathrm{pH}$ da solução. A atividade alelopática foi realizada em bioensaios de germinação e desenvolvimento da radícula e do hipocótilo, utilizando as plantas daninhas malicia (Mimosa pudica) e matapasto (Senna obtusifolia) como receptoras. Os efeitos do $\mathrm{pH}$ foram analisados na faixa de 3,0 a 9,0. Os triterpenos pentacíclicos friedelina e epifriedelinol isolados da parte aérea de $B$. brizantha apresentaram baixa atividade inibitória na germinação de sementes e no desenvolvimento da radícula e do hipocótilo das duas plantas daninhas. As duas substâncias apresentaram comportamento diferenciado em relação à variação do $\mathrm{pH}$ da solução, com inibições mais marcantes em relação à planta daninha mata-pasto.
\end{abstract}

Palavras-chave: Brachiaria brizantha, friedelina, epifriedelinol, gramínea forrageira, planta daninha.

ABSTRACT - This work aimed to isolate, identify and determine the allelopathic activity of the chemical substances produced by Brachiaria brizantha $c v$. Marandu and to verify the effects of the $\mathrm{pH}$ in the solution on the activity of these compounds. The allelopathic activity was evaluated based on germination bioassays and radicle and hypocotyl growth using the species 'malicia' (Mimosa pudica) and 'mata-pasto' (Senna obtusifolia) as receptors. The effect of pH was analyzed in a range from 3.0 to 9.0. The pentacyclic triterpenes friedelin and epifriefelinol isolated from the shoots of B. brizantha showed a low inhibitory activity against seed germination and radicle and hypocotyl growth of the two receptor plants evaluated. The pentacyclic triterpenes friedelin and epifrifelinol presented differentiated behaviors in relation to the $\mathrm{pH}$ variation in the solution, with stronger inhibition activity against the weed 'mata-pasto'.

Keywords: Brachiaria brizantha, friedelin, friedelinol, Gramineae, weed.

\section{INTRODUÇÃO}

Na região amazônica, assim como nas demais regiões pastoris brasileiras, as pastagens constituem, se não a única, a principal fonte de alimento para bovídeos em pastejo. Dessa forma, o sucesso da atividade pecuária depende, em grande parte, da qualidade da pastagem como alimento. Dentre as muitas espécies de gramineas forrageiras disponiveis para uso pelos produtores, o gênero Brachiaria merece destaque, pelo seu potencial de produção de forragem e pela capacidade de adaptação às mais variadas características de solo e clima predominantes no Brasil. Entre as diferentes espécies desse gênero, Brachiaria brizantha cv. Marandu assume importância destacada, sendo responsável pela maior parte das

1 Recebido para publicação em 6.8.2007 e na forma revisada em 5.3.2008.

2 Universidade Federal do Pará, Rua Augusto Corrêa, 01. 66075-900, Belém, Pará. ${ }^{3}$ Embrapa Amazônia Oriental, Trav. Dr. Enéas Pinheiro, S/N.66095-100, Belém-Pará. 
pastagens formadas no Brasil, em especial na última década, quando substituiu extensa área cultivada por outras gramíneas forrageiras.

A identificação de atividade potencialmente alelopática em espécies de gramíneas forrageiras se reveste da maior importância em se tratando de estratégia de manejo das pastagens quando se pensa na possibilidade que esse fato representa em termos de maior estabilidade da pastagem, formação de estandes mais densos, redução nos investimentos de manutenção do pasto e aumento da vida útil da pastagem. Além desses aspectos, essa prática pode favorecer a redução na utilização de herbicidas para controle de plantas daninhas, refletindo na diminuição dos danos ambientais decorrentes do seu uso e na melhoria da qualidade de saúde humana e da vida silvestre. Esses e outros aspectos decorrentes do uso sistemático de produtos sintéticos são discutidos nos trabalhos de Killham \& Foster (1996) e Anaya (1999).

As informações disponiveis sobre atividade alelopática em espécies de plantas forrageiras são limitadas, porém avanços expressivos foram conseguidos nos últimos anos. Para as espécies do gênero Brachiaria, atividades alelopáticas foram identificadas por Almeida (1993) e Carvalho (1993), em extratos aquosos da parte aérea. Chou (1989) isolou e identificou, em $B$. mutica, diferentes substâncias com atividade alelopática, como é o caso dos ácidos ferúlico, vanílico, $p$-hidroxibenzóico e $p$-hidroxifenilacético. Souza Filho et al. (2005) isolaram e identificaram na parte aérea de $B$. humidicola o ácido $p$-cumárico, o qual evidenciou intensa atividade alelopática inibitória da germinação de sementes e do desenvolvimento de plantas daninhas de áreas de pastagens cultivadas.

Especificamente em relação a $B$. brizantha cv. Marandu, atividade alelopática inibitória da germinação de sementes e do desenvolvimento da radícula e do hipocótilo de diferentes plantas daninhas foi documentada por Souza Filho et al. (1997a). Estudos desenvolvidos com essa forrageira indicaram atividades em diferentes frações da planta, como sementes, parte aérea e radícula, sendo a parte aérea a principal fonte de substâncias químicas solúveis em água, com atividade alelopática (Souza Filho et al., 1997b). Essas evidências apontam para a existência de metabólitos químicos envolvidos nesses efeitos, sendo o isolamento e identificação passo importante para o entendimento dos seus mecanismos de ação. Paralelamente, estudos visando o aumento da atividade inibitória desses metabólitos são importantes no contexto da estratégia de uso dessas substâncias como controle alternativo das plantas daninhas.

Este trabalho teve por objetivos isolar, identificar e caracterizar a atividade alelopática de substâncias químicas produzidas pela graminea forrageira Brachiaria brizantha cv. Marandu e, ao mesmo tempo, determinar as variações na atividade das substâncias em função da variação do $\mathrm{pH}$ da solução.

\section{MATERIAL E MÉTODOS}

\section{Coleta e preparo do material vegetal}

A parte aérea (folhas + colmos) do capimmarandu (Brachiaria brizantha cv. Marandu) foi coletada na fazenda experimental da Embrapa Amazônia Oriental, localizada em Belém, Pará. Por ocasião da coleta, as plantas não estavam com inflorescências ou produzindo sementes. $\mathrm{O}$ corte das plantas foi realizado a $10 \mathrm{~cm}$ de altura do solo. Após a coleta, o material foi mantido em estufa de circulação forçada de ar por 72 horas, à temperatura constante de $40{ }^{\circ} \mathrm{C}$. Em seguida, processou-se a trituração em moinho tipo Wiley e acondicionou-se o material em sacos de papel.

\section{Isolamento e identificação das substâncias quimicas}

O material vegetal $(4,95 \mathrm{~kg})$ seco e moído foi extraído em temperatura ambiente com $6 \mathrm{~L}$ de hexano durante 72 horas. Após filtragem e evaporação do solvente sob pressão reduzida, foram obtidos $25,5 \mathrm{~g}$ de extrato bruto hexânico (EBH). Dezoito gramas do EBH foram submetidos à cromatografia em coluna por via úmida (CCVU) filtrante, usando como adsorvente sílica-gel e, como eluente, seqüencialmente, os solventes hexano, diclorometano, acetato de etila e metanol. Foram utilizados 3,5 L de cada solvente, e, após evaporação, foram obtidos os filtrados hexânico $(1,85 \mathrm{~g})$, diclorometânico $(5,75 \mathrm{~g})$, acetato de etila $(6,93 \mathrm{~g})$ e 
metanólico $(3,42 \mathrm{~g})$. Os extratos foram analisados por cromatografia de camada delgada comparativa (CCDC) e por $\mathrm{RMN}^{-1} \mathrm{H}$, indicando impurezas no filtrado diclorometânico. Devido a isso, o filtrado diclorometânico $(3,0 \mathrm{~g})$ foi submetido a fracionamento cromatográfico em coluna (CC), utilizando-se sílica-gel como adsorvente e, como eluentes, misturas de solventes hex./AcOEt e AcOEt/MeOH em ordem crescente de polaridade. Foram coletadas 79 alíquotas, com volume médio de $100 \mathrm{~mL}$ cada. Após análise via CCDC, as alíquotas foram reunidas em 13 frações (F1-F13), de acordo com seus perfis cromatográficos. A fração $\mathrm{F} 1$ (42 mg) foi refracionada em CC, utilizando-se sílica-gel como adsorvente e, como eluentes, misturas de solventes hex/AcOEt em polaridade crescente, fornecendo $13,0 \mathrm{mg}$ da substância 1, identificada como friedelina (Figura 1). A fração F3 apresentou-se como um sólido impuro amarelado e foi submetida a processo de lavagem com hexano gelado, obtendo-se 17,4 mg de um sólido branco identificado como epifriedelinol (2) (Figura 1). As substâncias foram identificadas via análise dos espectros de $\mathrm{RMN}-{ }^{1} \mathrm{H}$ e $\mathrm{RMN}-{ }^{13} \mathrm{C}$ (Tabela 1$)$ e comparação com dados da literatura (Aragão, 1990; Ahmad \& Rahman, 1994).

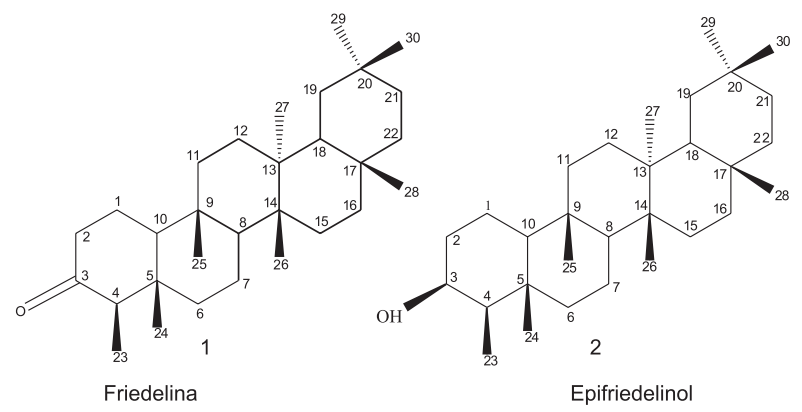

Figura 1 - Estrutura química das substâncias friedelina e epifriedelinol.

\section{Análise da atividade alelopática}

As atividades alelopáticas das substâncias químicas foram realizadas em dois experimentos distintos. No primeiro, foram analisados os efeitos das substâncias isoladamente e em mistura (em par). No segundo experimento, foi avaliada a interferência do $\mathrm{pH}$ da solução na atividade alelopática das substâncias. Em ambos os experimentos, as substâncias químicas foram testadas em concentração de $50 \mathrm{mg} \mathrm{L}^{-1}$, tendo como solvente o metanol. Como plantas receptoras, foram utilizadas as plantas daninhas de áreas de pastagens cultivadas: malícia (Mimosa pudica) e mata-pasto (Senna obtusifolia).

A germinação foi monitorada em períodos de 10 dias, com contagens diárias e eliminação das sementes germinadas. Foram consideradas sementes germinadas aquelas que apresentavam extensão radicular igual ou superior a 2,00 mm (Juntila, 1976; Duram \& Tortosa, 1985). Os bioensaios foram desenvolvidos em condições controladas: $25{ }^{\circ} \mathrm{C}$ de temperatura constante e fotoperiodo de 12 horas para germinação de sementes e $25^{\circ} \mathrm{C}$ de temperatura constante e fotoperiodo de 24 horas para o bioensaio de desenvolvimento da radícula e do hipocótilo. No bioensaio de germinação de sementes, cada placa de Petri de 9,0 cm de diâmetro, forrada com uma folha de papel-filtro qualitativo, recebeu 30 sementes previamente tratadas para a quebra de dormência, conforme Souza Filho et al. (1998a). Nos bioensaios de desenvolvimento da radícula e do hipocótilo, cada placa de Petri de $9,0 \mathrm{~cm}$ de diâmetro, forrada com uma folha de papel-filtro qualitativo, recebeu três sementes pré-germinadas e, no final de 10 dias de crescimento, mediu-se o comprimento da radícula e do hipocótilo.

No experimento de avaliação do efeitos do $\mathrm{pH}$, foram preparadas soluções com $\mathrm{pH} 3,0,5,0$, 7,0 e 9,0, utilizando-se ácido clorídrico ( $\mathrm{HCl}$ ) para baixar o $\mathrm{pH}$ e hidróxido de potássio $(\mathrm{KOH})$ para elevá-1o. As substâncias foram testadas na concentração de $50 \mathrm{mg} \mathrm{L}^{-1}$. Nesse caso, os efeitos foram analisados apenas sobre a germinação de sementes, em bioensaios semelhantes àqueles descritos para o primeiro experimento.

Em todos os bioensaios, cada placa de Petri de $9,0 \mathrm{~cm}$ de diâmetro recebeu $3,0 \mathrm{~mL}$ da solução-teste; as soluções foram adicionadas apenas uma vez, quando do início de cada bioensaio, sendo, a partir de então, adicionada apenas água destilada, sempre que necessário, para manter a concentração inicial. Especificamente para o bioensaio em que foram 
analisados os efeitos do $\mathrm{pH}$, em vez de água destilada, adicionou-se solução aquosa de $\mathrm{pH}$ correspondente.

\section{Delineamento experimental e análise estatistica}

O delineamento experimental para todos os bioensaios foi inteiramente casualizado, com quatro repetições. Para o primeiro experimento, utilizou-se como tratamento testemunha a água destilada. Os dados foram analisados pelo teste $\mathrm{F}$, e as médias, comparadas pelo teste de Tukey (5\%). Na análise dos dados utilizou-se o programa SAS (SAS, 1989).

\section{RESULTADOS E DISCUSSÃO}

Em trabalho anterior (Corrêa et al., 1998), demonstrou-se o potencial alelopático do EBH perante as plantas invasoras de pastagens Mimosa pudica (malícia) e Senna obtusifolia (mata-pasto). No presente trabalho, foram realizados o isolamento e a identificação de substâncias presentes no extrato e procedeu-se à análise de suas propriedades alelopáticas em diferentes $\mathrm{pH}$.

\section{Substâncias químicas isoladas e identificadas}

Os espectros de $\mathrm{RMN}^{13} \mathrm{C}$ e DEPT da substância 1 (Tabela 1) permitiram identificar os sinais referentes aos carbonos quaternários (C), terciários $(\mathrm{CH})$, secundários $\left(\mathrm{CH}_{2}\right)$ e primários $\left(\mathrm{CH}_{3}\right)$. A absorção em 203,0 ppm é referente ao carbono $\mathrm{C} 3$ da carbonila. Os dados espectrais de $\mathrm{RMN}{ }^{1} \mathrm{H}$ e de $\mathrm{RMN}{ }^{13} \mathrm{C}$ da substância, em comparação com dados da literatura (Aragão et al., 1990), permitiram identificar a substância 1 como o triterpeno pentacíclico friedelina. Os espectros de RMN ${ }^{13} \mathrm{C}$ e DEPT da substância 2 indicaram a presença de carbonos quaternários $(\mathrm{C})$, terciários $(\mathrm{CH})$, secundários $\left(\mathrm{CH}_{2}\right)$ e primários $\left(\mathrm{CH}_{3}\right)$, com destaque para a absorção em $72,76 \mathrm{ppm}$, referente ao sinal do carbono oximetínico (C3) (Tabela 1). Os dados espectrais de $\mathrm{RMN}{ }^{1} \mathrm{H}$ e de $\mathrm{RMN}{ }^{13} \mathrm{C}$ da substância, em comparação com dados da literatura (Aragão et al., 1990), permitiram identificar a substância 2 como o triterpeno pentacíclico epifriedelinol. A estrutura química desses dois triterpenos é apresentada na Figura 1.
Tabela 1 - Dados de RMN ${ }^{13} \mathrm{C}$ - DEPT ( $75 \mathrm{MHz}, \mathrm{CDCl}_{3}$ ) das substâncias químicas friedelina (1) e epifriedelinol (2) em comparação com dados da literatura (Aragão et al., 1990)

\begin{tabular}{|c|c|c|c|c|}
\hline $\mathrm{C}$ & 1 (Exp.) & 1 (Lit.) & 2 (Exp.) & 2 (Lit.) \\
\hline 1 & $22,2\left(\mathrm{CH}_{2}\right)$ & $22,7\left(\mathrm{CH}_{2}\right)$ & $15,7\left(\mathrm{CH}_{2}\right)$ & $15,8\left(\mathrm{CH}_{2}\right)$ \\
\hline 2 & $41,5\left(\mathrm{CH}_{2}\right)$ & $41,8\left(\mathrm{CH}_{2}\right)$ & $35,2\left(\mathrm{CH}_{2}\right)$ & $35,2\left(\mathrm{CH}_{2}\right)$ \\
\hline 3 & $213,3(\mathrm{C})$ & $213,0(\mathrm{C})$ & $72,7(\mathrm{C}-\mathrm{OH})$ & 72,7 \\
\hline 4 & $58,1(\mathrm{CH})$ & $58,2(\mathrm{CH})$ & $49,1(\mathrm{CH})$ & $49,2(\mathrm{CH})$ \\
\hline 5 & $42,1(\mathrm{CH})$ & $42,8(\mathrm{CH})$ & $41,2(\mathrm{C})$ & $41,2(\mathrm{C})$ \\
\hline 6 & $41,2\left(\mathrm{CH}_{2}\right)$ & $41,2\left(\mathrm{CH}_{2}\right)$ & $42,1\left(\mathrm{CH}_{2}\right)$ & $41,8\left(\mathrm{CH}_{2}\right)$ \\
\hline 7 & $18,2\left(\mathrm{CH}_{2}\right)$ & $18,3\left(\mathrm{CH}_{2}\right)$ & $17,5\left(\mathrm{CH}_{2}\right)$ & $17,6\left(\mathrm{CH}_{2}\right)$ \\
\hline 8 & $53,0(\mathrm{CH})$ & $53,2(\mathrm{CH})$ & $53,1(\mathrm{CH})$ & $53,2(\mathrm{CH})$ \\
\hline 9 & $37,4(\mathrm{C})$ & $37,8(\mathrm{C})$ & $37,4(\mathrm{C})$ & $37,8(\mathrm{C})$ \\
\hline 10 & $59,4(\mathrm{CH})$ & $59,5(\mathrm{CH})$ & $61,3(\mathrm{CH})$ & $61,4(\mathrm{CH})$ \\
\hline 11 & $35,2\left(\mathrm{CH}_{2}\right)$ & $35,2\left(\mathrm{CH}_{2}\right)$ & $35,6\left(\mathrm{CH}_{2}\right)$ & $35,6\left(\mathrm{CH}_{2}\right)$ \\
\hline 12 & $32,3\left(\mathrm{CH}_{2}\right)$ & $32,4\left(\mathrm{CH}_{2}\right)$ & $33,4\left(\mathrm{CH}_{2}\right)$ & $32,9\left(\mathrm{CH}_{2}\right)$ \\
\hline 13 & $38,2(\mathrm{C})$ & $38,2(\mathrm{C})$ & $38,2(\mathrm{C})$ & $38,2(\mathrm{C})$ \\
\hline 14 & $39,6(\mathrm{C})$ & $39,7(\mathrm{C})$ & $39,6(\mathrm{C})$ & $39,7(\mathrm{C})$ \\
\hline 15 & $30,4\left(\mathrm{CH}_{2}\right)$ & $30,6\left(\mathrm{CH}_{2}\right)$ & $30,6\left(\mathrm{CH}_{2}\right)$ & $30,6\left(\mathrm{CH}_{2}\right)$ \\
\hline 16 & $35,9\left(\mathrm{CH}_{2}\right)$ & $36,1\left(\mathrm{CH}_{2}\right)$ & $36,0\left(\mathrm{CH}_{2}\right)$ & $36,1\left(\mathrm{CH}_{2}\right)$ \\
\hline 17 & $29,9(\mathrm{C})$ & $30,0(\mathrm{C})$ & $29,6(\mathrm{C})$ & $29,3(\mathrm{C})$ \\
\hline 18 & $42,7(\mathrm{CH})$ & $42,9(\mathrm{CH})$ & $42,8(\mathrm{CH})$ & $42,9(\mathrm{CH})$ \\
\hline 19 & $35,3\left(\mathrm{CH}_{2}\right)$ & $35,3\left(\mathrm{CH}_{2}\right)$ & $35,5\left(\mathrm{CH}_{2}\right)$ & $35,6\left(\mathrm{CH}_{2}\right)$ \\
\hline 20 & $28,1(\mathrm{C})$ & $28,2(\mathrm{C})$ & $28,1(\mathrm{C})$ & $28,2(\mathrm{C})$ \\
\hline 21 & $32,7\left(\mathrm{CH}_{2}\right)$ & $32,9\left(\mathrm{CH}_{2}\right)$ & $32,7\left(\mathrm{CH}_{2}\right)$ & $32,9\left(\mathrm{CH}_{2}\right)$ \\
\hline 22 & $39,2\left(\mathrm{CH}_{2}\right)$ & $39,3\left(\mathrm{CH}_{2}\right)$ & $39,2\left(\mathrm{CH}_{2}\right)$ & $39,3\left(\mathrm{CH}_{2}\right)$ \\
\hline 23 & $6,8\left(\mathrm{CH}_{3}\right)$ & $6,8\left(\mathrm{CH}_{3}\right)$ & $11,7\left(\mathrm{CH}_{3}\right)$ & $11,6\left(\mathrm{CH}_{3}\right)$ \\
\hline 24 & $14,6\left(\mathrm{CH}_{3}\right)$ & $14,1\left(\mathrm{CH}_{3}\right)$ & $16,3\left(\mathrm{CH}_{3}\right)$ & $16,4\left(\mathrm{CH}_{3}\right)$ \\
\hline 25 & $17,9\left(\mathrm{CH}_{3}\right)$ & $18,2\left(\mathrm{CH}_{3}\right)$ & $17,9\left(\mathrm{CH}_{3}\right)$ & $18,2\left(\mathrm{CH}_{3}\right)$ \\
\hline 26 & $18,6\left(\mathrm{CH}_{3}\right)$ & $18,6\left(\mathrm{CH}_{3}\right)$ & $18,2\left(\mathrm{CH}_{3}\right)$ & $18,6\left(\mathrm{CH}_{3}\right)$ \\
\hline 27 & $20,2\left(\mathrm{CH}_{3}\right)$ & $20,1\left(\mathrm{CH}_{3}\right)$ & $20,1\left(\mathrm{CH}_{3}\right)$ & $20,1\left(\mathrm{CH}_{3}\right)$ \\
\hline 28 & $32,0\left(\mathrm{CH}_{3}\right)$ & $32,1\left(\mathrm{CH}_{3}\right)$ & $32,1\left(\mathrm{CH}_{3}\right)$ & $32,1\left(\mathrm{CH}_{3}\right)$ \\
\hline 29 & $31,7\left(\mathrm{CH}_{3}\right)$ & $31,8\left(\mathrm{CH}_{3}\right)$ & $31,8\left(\mathrm{CH}_{3}\right)$ & $31,8\left(\mathrm{CH}_{3}\right)$ \\
\hline 30 & 35,0 & $35,0\left(\mathrm{CH}_{3}\right)$ & $34,9\left(\mathrm{CH}_{3}\right)$ & $35,0\left(\mathrm{CH}_{3}\right)$ \\
\hline
\end{tabular}

\section{Análise da atividade alelopática}

\section{Efeitos alelopáticos das substâncias}

Na concentração de $50 \mathrm{mg} \mathrm{L}^{-1}$, fridelina e epifriedelinol, individualmente, apresentaram baixo potencial para inibir a germinação das sementes das duas plantas daninhas, com efeito inibitório máximo da ordem de $17 \%$, promovido pela friedelina, sobre a germinação de mata-pasto. Comparativamente, os efeitos promovidos sobre a germinação das sementes de malícia não diferiram $(p>0,05)$ entre as duas substâncias, porém, nos efeitos sobre matapasto, friedelina se mostrou superior à epifriedelinol em $100 \%$. Por sua vez, quando aplicadas juntas (50 $\mathrm{mg} \mathrm{L}^{-1}$ de cada substância), as 
inibições sobre a germinação das sementes de malícia foram $50 \%$ mais elevadas, em relação às duas substâncias, e 94 e 300\% superior aos efeitos promovidos sobre as sementes de mata-pasto, por friedelina e epifriedelinol, respectivamente (Tabela 2).

Tabela 2 - Efeitos alelopáticos da friedelina (1) e epifriedelinol (2), isoladas e em par, sobre a germinação de sementes de duas plantas daninhas. Dados expressos em percentual de inibição em relação ao tratamento testemunha - água destilada

\begin{tabular}{|l|c|c|}
\hline \multirow{2}{*}{\multicolumn{1}{|c|}{ Substância }} & \multicolumn{2}{c|}{ Planta daninha } \\
\cline { 2 - 3 } & Malícia & Mata-pasto \\
\hline Friedelina & $10,0 \mathrm{Bb}$ & $17,0 \mathrm{Ba}$ \\
\hline Epifriedelinol & $10,0 \mathrm{Ba}$ & $8,0 \mathrm{Ca}$ \\
\hline Friedelina + epifriedelinol & $15,0 \mathrm{Ab}$ & $33,0 \mathrm{Aa}$ \\
\hline
\end{tabular}

Médias seguidas de letras iguais, maiúsculas na coluna e minúsculas na linha, não diferem pelo teste de Tukey (5\%).

Quando foram analisados os efeitos sobre o desenvolvimento da radícula (Tabela 3) e do hipocótilo (Tabela 4), observou-se que, ao contrário dos resultados obtidos sobre a germinação, o epifriedelinol demonstrou maior habilidade para inibir esses dois fatores da planta do que a friedelina. Quanto ao desenvolvimento da radícula de malícia e mata-pasto, epifriedelinol promoveu inibições de 250 e $50 \%$ superiores às da friedelina. Essa superioridade também foi observada nos efeitos sobre o desenvolvimento do hipocótilo, embora a intensidade dos efeitos e as diferenças entre as duas substâncias tenham sido de menor magnitude.

À semelhança dos efeitos observados sobre a germinação das sementes, friedelina e epifriedelinol, quando juntos, mostraram maior poder para inibir tanto o desenvolvimento da radícula como o do hipocótilo das duas espécies de plantas receptoras, embora nem sempre essa superioridade tenha sido estatisticamente diferente $(p>0,05)$. Os resultados indicam, ainda, que o potencial das duas substâncias, quando aplicadas juntas, esteve mais para os efeitos de epifriedelinol do que para fridelina, em especial para os efeitos sobre o desenvolvimento da radícula (Tabela 3) e do hipocótilo (Tabela 4).

Nenhum efeito alelopático para as duas substâncias isoladas e testadas no presente
Tabela 3 - Efeitos alelopáticos da friedelina (1) e epifriedelinol (2), isoladas e em par, sobre o desenvolvimento da radícula de duas plantas daninhas. Dados expressos em percentual de inibição em relação ao tratamento testemunha - água destilada

\begin{tabular}{|l|c|c|}
\hline \multirow{2}{*}{\multicolumn{1}{|c|}{ Substância }} & \multicolumn{2}{c|}{ Planta daninha } \\
\cline { 2 - 3 } & Malícia & Mata-pasto \\
\hline Friedelina & $9,3 \mathrm{Ca}$ & $7,3 \mathrm{Ba}$ \\
\hline Epifriedelinol & $30,6 \mathrm{Ba}$ & $11,5 \mathrm{Ab}$ \\
\hline Friedelina + epifriedelinol & $34,0 \mathrm{Aa}$ & $13,5 \mathrm{Ab}$ \\
\hline
\end{tabular}

Médias seguidas de letras iguais, maiúsculas na coluna e minúsculas na linha, não diferem pelo teste de Tukey (5\%).

Tabela 4 - Efeitos alelopáticos da friedelina (1) e epifriedelinol (2), isoladas e em par, sobre o desenvolvimento do hipocótilo de duas plantas daninhas. Dados expressos em percentual de inibição em relação ao tratamento testemunha - água destilada

\begin{tabular}{|l|c|c|}
\hline \multirow{2}{*}{\multicolumn{1}{|c|}{ Substância }} & \multicolumn{2}{c|}{ Planta daninha } \\
\cline { 2 - 3 } & Malícia & Mata-pasto \\
\hline Friedelina & $11,0 \mathrm{Ca}$ & $5,4 \mathrm{Cb}$ \\
\hline Epifriedelinol & $13,1 \mathrm{Bb}$ & $20,3 \mathrm{Aa}$ \\
\hline Friedelina + epifriedelinol & $20,7 \mathrm{Aa}$ & $22,4 \mathrm{Aa}$ \\
\hline
\end{tabular}

Médias seguidas de letras iguais, maiúsculas na coluna e minúsculas na linha, não diferem pelo teste de Tukey (5\%).

trabalho foi encontrado na literatura. Entretanto, friedelina e epifriedelinol pertencem à classe dos terpenóides, especificamente triterpenóides, os quais têm sido relacionados a intensas atividades alelopáticas, conforme mencionado por Fischer et al. (1994), Fischer (1986) e Lotina-Hensen et al. (1992). Monoterpenos e sesquiterpenos são os terpenóides mais envolvidos em alelopatia (Putnam, 1988; Abrahim et al., 2000; Mizutani, 1999).

Recentemente, Martins et al. (2006) mencionaram atividade alelopática para soluções de solo cultivado com a Brachiaria brizantha cv. Marandu. Esses dados mostram que substâncias químicas com atividades alelopáticas são liberadas por essa graminea forrageira para $o$ ambiente, pelas mais variadas formas já estabelecidas, e se acumulam no solo em níveis que podem interferir na comunidade de plantas, quer inibindo a germinação de sementes, quer comprometendo o desenvolvimento das plantas afetadas. Dessa forma, fridelina e epifriedelinol, ou outras substâncias com 
atividade alelopática, ainda não identificadas, podem estar envolvidas nesse processo.

Muitos dos resultados encontrados na literatura apontam para efeitos semelhantes aos do presente trabalho, nos quais as substâncias químicas com propriedades alelopáticas juntas evidenciam maior potencial alelopático do que isoladamente. Os trabalhos de Vokou et al. (2003), Einhellig (1995) e Weidenhamer et al. (1994) são exemplos desse tipo de abordagem. Entretanto, esses resultados devem ser vistos com certa reserva, em especial quando se imagina a possibilidade da ocorrência de sinergismo entre as substâncias. Para os resultados deste trabalho, propõe-se o termo "ação aditiva”, pois a concentração, no caso das substâncias analisadas em combinação (em par), dobra em relação àquela de cada substância isoladamente.

\section{Efeitos do pH na atividade alelopática das substâncias}

Friedelina e epifriedelinol, isolada e conjuntamente, apresentaram comportamento diferenciado em relação ao $\mathrm{pH}$ da solução. Para friedelina e friedelina + epifriedelinol não foram observadas diferenças $(p>0,05)$ na atividade alelopática, na faixa de $\mathrm{pH}$ de 3,0 a 9,0, sobre a germinação das sementes de malícia.
Já para epifriedelinol, a atividade alelopática inibitória da germinação foi mais intensa na faixa de $\mathrm{pH}$ de 5,0 a 7,0 (Tabela 5).

Em relação aos efeitos sobre a germinação de sementes da planta daninha mata-pasto (Tabela 6), os resultados indicaram diferença significativa $(\mathrm{p}<0,05)$ para as substâncias isoladas e juntas (em par). Os efeitos da friedelina foram maximizados em condições de $\mathrm{pH} 3,0$ e 5,0. Para epifriedelinol, a atividade foi máxima em $\mathrm{pH}$ 9,0, enquanto para friedelina + epifriedelinol os efeitos foram potencializados em $\mathrm{pH}$ extremos (3,0 e 9,0). Esses dados indicam que o fator espécie receptora é determinante nos resultados e que as substâncias atuam, em relação à variação do pH da solução, de forma independente, sendo mais intensa para determinada substância.

Aparentemente, as exigências dessas duas substâncias, em relação ao fator $\mathrm{pH}$ da solução, são diferenciadas. Entretanto, os acréscimos observados em função do $\mathrm{pH}$ na faixa de 5,0 a 7,0 foram menores para malícia, quando comparado com a espécie mata-pasto. Esse dado assume aspecto relevante quando se pensa nessa estratégia para aumentar a atividade alelopática dessas duas substâncias. Em relação à espécie mata-pasto, os resultados foram mais marcantes, o que justifica a utilização do processo.

Tabela 5 - Variações nos efeitos alelopáticos da friedelina (1) e epifriedelinol (2), isoladas e em par, sobre a germinação de sementes da planta daninha malícia, em função do $\mathrm{pH}$ da solução. Dados expressos em percentual de germinação

\begin{tabular}{|l|c|c|c|c|}
\hline \multirow{2}{*}{ Substância } & \multicolumn{3}{c|}{$\mathrm{pH}$} \\
\cline { 2 - 5 } & 3,0 & 5,0 & 7,0 & 9,0 \\
\hline Friedelina & $77,0 \mathrm{Aa}$ & $80,0 \mathrm{Aa}$ & $80,0 \mathrm{Aa}$ & $78,0 \mathrm{Ba}$ \\
\hline Epifriedelinol & $80,0 \mathrm{Ab}$ & $77,0 \mathrm{Abc}$ & $75,0 \mathrm{Bc}$ & $85,0 \mathrm{Aa}$ \\
\hline Friedelina + Epifriedelinol & $80,0 \mathrm{Aa}$ & $80,0 \mathrm{Aa}$ & $78,0 \mathrm{ABa}$ & $77,0 \mathrm{Ba}$ \\
\hline
\end{tabular}

Médias seguidas de letras iguais, maiúsculas na coluna e minúsculas na linha, não diferem pelo teste de Tukey (5\%).

Tabela 6 - Variações nos efeitos alelopáticos da friedelina (1) e epifriedelinol (2), isoladas e em par, sobre a germinação de sementes da planta daninha mata-pasto, em função do pH da solução. Dados expressos em percentual de germinação

\begin{tabular}{|l|c|c|c|c|}
\hline \multirow{2}{*}{ Substância } & \multicolumn{4}{c|}{$\mathrm{pH}$} \\
\cline { 2 - 5 } & 3,0 & 5,0 & 7,0 & 9,0 \\
\hline Friedelina & $20,0 \mathrm{Cc}$ & $45,0 \mathrm{Cb}$ & $55,0 \mathrm{Aa}$ & $53,0 \mathrm{Aa}$ \\
\hline Epifriedelinol & $63,0 \mathrm{Aa}$ & $55,0 \mathrm{Ab}$ & $54,0 \mathrm{Ab}$ & $48,0 \mathrm{Bc}$ \\
\hline Friedelina + Epifriedelinol & $45,0 \mathrm{Bc}$ & $50,0 \mathrm{Bb}$ & $55,0 \mathrm{Aa}$ & $46,0 \mathrm{Bc}$ \\
\hline
\end{tabular}

Médias seguidas de letras iguais, maiúsculas na coluna e minúsculas na linha, não diferem pelo teste de Tukey (5\%). 
Número limitado de pesquisas que analisam os efeitos do $\mathrm{pH}$ na atividade alelopática de substâncias químicas é encontrado na literatura. Um dos poucos exemplos é o trabalho de Harper \& Balke (1981), no qual os autores observaram efeitos marcantes do $\mathrm{pH}$, na atividade do ácido salicílico, sobre a absorção de $\mathrm{K}^{+}$.

Batra \& Kuma (1993) estudaram os efeitos da variação do $\mathrm{pH}$ sobre a germinação de sementes e observaram que esta é afetada em condições extremamente ácidas ou alcalinas. Especificamente para as plantas daninhas malícia e mata-pasto, Souza Filho et al. (1998b, 2001) não encontraram variações na germinação das sementes em função do $\mathrm{pH}$ na faixa de 3,0 a 11,0 . O conjunto dessas informações permite inferir que as variações observadas na atividade alelopática das substâncias friedelina e epifriedelinol não se devem aos efeitos específicos do $\mathrm{pH}$ na germinação das sementes. Aparentemente, a maior ou menor atividade alelopática das duas substâncias está associada a alguma especificidade em relação ao $\mathrm{pH}$.

\section{LITERATURA CITADA}

ABRAHIM, D. et al. Effects of four monoterpenes on germination, primary root growth and mitochondrial respiration of maize. J. Chem. Ecol., v. 26, n. 3, p. 611-624, 2000.

ALMEIDA, A. R. P. Efeitos alelopáticos de espécies de Brachiaria Griseb sobre algumas leguminosas tropicais. 1993. 73 f. Dissertação (Mestrado em Zootecnia) Universidade de São Paulo, Piracicaba, 1993.

AHMAD, V. U.; RAHMAN, A. Pentacyclic triterpenoids, handbook of natural products data. New York: Elsevier, 1994. $1490 \mathrm{p}$.

ANAYA, A. L. Allelopathy as a tool in the management of biotic resources in agroecosystems. Crit. Rev. Plant Sci., v. 18, n. 6, p. $697-739,1999$.

ARAGÃO, P. C. A. et al. Substâncias naturais isoladas de Stigmaphyllon tomentosum e Birsonima variabili. Química Nova, v. 13, n. 4, p. 254-259, 1990

BATRA, L.; KUMAR, A. Effects of alkalinity on germination, growth and nitrogen content of whistling (Casuarina equisetifolia) and bufwood (C. galuca). Ind. J. Agric. Sci., v. 63, n. 7, p. 412-416, 1993.
CARVALHO, S. J. C. Caracterização dos efeitos alelopáticos de Brachiaria brizantha cv. Marandu no estabelecimento das plantas de Stylosanthes guianensis var. vulgaris cv. Bandeirante. 1993. 72 f. Dissertação (Mestrado em Zootecnia) - Universidade Federal de Viçosa, Viçosa, MG, 1993.

CHOU, C. H. Allelopathic of subtropical vegetation in Taiwan. IV. Comparative phytotoxic nature of leachate four subtropical grasses. J. Chem. Ecol., v. 15, n. 7, p. 21492159, 1989.

CORRÊA, M. J. C. et al. Avaliação preliminar da atividade alelopática de Brachiaria brizantha (GRAMINEAE). In: CONGRESSO BRASILEIRO DE QUÍMICA, 38., 1998, São Luís. Anais... São Paulo: Sociedade Brasileira de Química, 1998. v. 1. p. 397-398.

DURAN, R. D.; TORTOSA, M. E. The effect of mechanical and chemical scarification on germination of charlock (Sinapsis arvensis L.) seeds. Seed Sci. Technol., v. 13, n. 1, p. 155-163, 1985.

EINHELLIG, F. A. Allelopathy: Current status and future goals. In: INDERJIT, S.; DAKSHINI, K. M. M.; EINHELLI, F. A. Allelopathy: Organisms, processes and applications. Washington: 1995. p. 1-24. (ACS. Symposium Series).

FISCHER, N. H. The function of mono and sesquiterpenes as plant germination and growth regulation. In: PUTNAM, A. R.; TANG, C. S. (Eds.). The science of allelopathy. New York: John Wiley, 1986. p. 203-218.

FISCHER, N. H et al. In research of allelopathy in the Florida scrubs: the role of terpenoids. J. Chem. Ecol., v. 20, n. 6, p. 1355-1358, 1994.

HARPER, J. R.; BALKE, N. E. Characterization of the inhibition of $\mathrm{k}+$ absorption in oat roots by salicylic acid. Plant Physiol., v. 68, n. 6, p. 1349-1353, 1981.

JUNTILA, O. Seed and embryo germination in S. vulgaris and $S$. reflexa as affected by temperature during seed development. Physiol. Plant., v. 29, p. 264-268, 1976.

KILLHAM, K.; FOSTER, R. Soil ecology. Cambridge: University Press, 1996. 242 p.

LOTINA-HENNSEN, B. et al. Inhibition of oxygen evolution by Zaluzanin-C. J. Chem. Ecol., v. 18, n. 11, p. 1891-1990, 1992.

MARTINS, D.; MARTINS, C. C.; COSTA, N. V. Potencial alelopático de soluções de solo cultivado com Brachiaria brizantha: efeitos sobre a germinação de gramíneas forrageiras e plantas daninhas de pastagens. Planta Daninha, v. 24, n. 1, p. 61-70, 2006. 
MIZUTAMI, J. Selected allelochemicals. Crit. Rev. Plant Sci., v. 18, n. 5, p. 653-671, 1999.

PUTNAM, A. R. Allelochemicals from plants as herbicides. Weed Technol., v. 2, n. 4, p. 510-518, 1988.

SAS- Institute. Statistical Analysis System. User's guide. Version 6. 4.ed. North Caroline: 1989. 846 p.

SOUZA FILHO, A. P. S.; FERREIRA, A. A. G.; BAYMA, J. C. Aleloquímico produzido pela gramínea forrageira Brachiaria humidicola. Planta Daninha, v. 23, n. 1, p. 2532,2005

SOUZA FILHO, A. P. S.; DUTRA, S.; SILVA, M. A. M. M Métodos de superação da dormência de sementes de plantas daninhas de pastagens cultivadas da Amazônia. Planta

Daninha, v. 16, n. 1, p. 2-11, 1998a

SOUZA FILHO, A. P. S. et al. Efeitos de diferentes substratos e da profundidade de semeadura na germinação de sementes de mata-pasto e malva. Planta Daninha, v. 16 , n. 1, p. $67-74,1998 b$
SOUZA FILHO, A. P. S.; RODRIGUES, L. R. A.;

RODRIGUES, T. J. D. Inibição da germinação e alongamento da radícula de invasoras de pastagens pelos extratos aquosos de gramíneas forrageiras tropicais. Pasturas Trop., v. 19, n. 1, p. $45-50,1997 \mathrm{a}$

SOUZA FILHO, A. P. S.; RODRIGUES, L. R. A.; RODRIGUES, T. J. D. Potencial alelopático de forrageiras tropicais: efeitos sobre invasoras de pastagens. Planta

Daninha, v. 15, n. 1, p. 53-60, 1997b

SOUZA FILHO, A.P. S. et al. Germinação de sementes de plantas daninhas de pastagens cultivadas: Mimosa pudica e Ipomoea asarifolia. Planta Daninha, v. 19, n. 1, p. 23-31, 2001.

VOKOU, D. et al. Effects of monoterpenoids, acting alone or in pairs, on seed germination and subsequent seedling growth. J. Chem. Ecol., v. 29, n. 10, p. 2281-2301, 2003

WEIDENHAMER, J. D. et al. Allelopathic potential of menthofuran monoterpenes from Calamuntha ashei.

J. Chem. Ecol., v. 20, p. 3345-3359, 1994 